\title{
A Genetic System for Pachysolen tannophilus, a Pentose-fermenting Yeast
}

\author{
By ALLEN P. JAMES* AND DIANA M. ZAHAB \\ Division of Biological Sciences, National Research Council of Canada, 100 Sussex Drive, Ottawa, \\ Ontario K1A 0R6, Canada
}

(Received 14 December 1981)

The genetics of Pachysolen tannophilus, a yeast able to ferment xylose to alcohol, was investigated. This yeast is a strongly homothallic organism in which the haplophase is predominant. Typically, diploidy is a consequence of fusion of two mitotic products within a specialized conjugant cell. The diploid nucleus proceeds directly to meiosis and the production of a fourspored ascus. A technique for isolating both homozygous and heterozygous diploids has been devised. The species is amenable to tetrad analysis, and is well-suited to the study of pentose fermentation in yeast.

\section{INTRODUCTION}

It has recently been found that the yeast Pachysolen tannophilus is capable of fermenting xylose, an aldopentose, to ethanol (Schneider et al., 1981). This ability and the metabolic pathway involved are of obvious intrinsic interest. However, the fact that this yeast has the ability to ferment xylose is also of immediate practical significance; xylose is found in the hemicellulose fraction of many cellulosic materials, but is not utilized in commercial fermentation processes. The organism is thus of potential importance to industry; it may prove useful in providing a more efficient method of converting biomass to energy.

It is possible that $P$. tannophilus is adequate for commercial purposes as it occurs in nature, but it is reasonable to suppose that more competent strains can be produced through genetic engineering. Such engineering, whether employing the older technique of mutation, selection and breeding, or the newer techniques of recombinant-DNA, almost certainly requires a knowledge of its genetics. To date, such information is scanty.

Boidin \& Adzet (1957), who discovered the species, confined their more genetically-oriented observations to descriptions of vegetative reproduction and sporulation. Briefly, vegetative reproduction occurs by budding, and sporulation occurs with ascophore formation, whereby a cell projects a long tube at the tip of which a four-spored ascus appears. Of four strains isolated by Boidin \& Adzet (1957), three sporulated with a low frequency and one with a distinctly higher frequency. In the case of the former strains, the authors noted that a small cell was often attached to or near the mother cell that formed the base of the ascophore. Such attachments were absent in the latter strain, and Wickerham (1970) proposed that this strain was diploid, the others haploid. He also concluded that the species was homothallic; the clones derived from individual ascospores themselves produced asci with the low frequency characteristic of haploids.

This investigation is concerned with the genetics of $P$. tannophilus. It has been demonstrated that this yeast is amenable to genetic manipulation despite the strongly autogamous nature of its sexuality. The haplophase is apparently predominant, the diplophase normally being restricted to a single nucleus. This nucleus usually results from fusion of two haploid nuclei within a 'conjugant' cell, and apparently proceeds directly to meiosis. Nevertheless, laboratory methods are available for the isolation of mitotically stable diploids. Auxotrophic mutants are easily obtained, and the yeast is amenable to tetrad analysis. 


\section{METHODS}

The strains of $P$. tannophilus were those isolated by Boidin \& Adzet (1957), IRIC 145 (NRRL Y2460), IRIC 146 (NRRL Y2461), IRIC 152 (NRRL Y2462), and IRIC 153 (NRRL Y2463).

Two media were selected for general use, one conducive to vegetative growth, the other to sporulation. That found most satisfactory for vegetative growth was the standard yeast extract/peptone/dextrose agar medium (YEPD) which contains $\left(\mathrm{g}^{-1}\right.$ ): yeast extract (10), peptone (20), dextrose (20) and agar (20). That selected for sporulation was yeast extract/malt extract agar medium (YM) which contains $\left(\mathrm{g}^{-1}\right)$ : yeast extract (4), malt extract (10), dextrose (4) and agar (20) (Shirling \& Gottlieb, 1966). The $\mathrm{pH}$ was adjusted to $5 \cdot 0$ prior to autoclaving.

Mutations were induced by UV-irradiation. A heavy suspension of washed stationary cells $\left(10^{8} \mathrm{ml}^{-1}\right)$ was exposed to $200 \mathrm{~J} \mathrm{~m}^{-2}$, diluted appropriately, and plated on YEPD. Survival was about $2 \%$. After incubation for $3 \mathrm{~d}$ at $30^{\circ} \mathrm{C}$, colonies were replica-plated to omission media for detection of auxotrophs.

Genetic techniques were standard except for tetrad analysis. The tetrads of $P$. tannophilus are released from asci as they mature and may be isolated directly when a sporulating culture is streaked on an agar medium. The tetrads can be distinguished from vegetative cells because they are more refractile. However, the spores are somewhat sticky; this condition was alleviated by pretreatment for a few minutes with a weak solution $(1: 40)$ of cytohelicase.

\section{RESULTS AND DISCUSSION}

\section{Vegetative growth and sporulation of haploid strains}

The four strains of $P$. tannophilus were alike with respect to cell size and growth characteristics. An indication of their ploidy was obtained from their induced mutability, determined using UV light. The rate at which auxotrophs were induced was very similar to that expected of haploid Saccharomyces cerevisiae. With this information, all were provisionally classified as haploid.

All the strains grew satisfactorily on yeast nitrogen base (YNB) without added amino acids. Generation time for vegetative cells was about $135 \mathrm{~min}$ on solid YEPD at $30^{\circ} \mathrm{C}$.

Budding of the small oval cells was strongly bipolar, a fact already noted by Boidin $\&$ Adzet (1957). The first bud of a daughter cell was distal to its point of attachment to the mother cell. Subsequent buds might be proximal or distal to their immediate predecessors, but tended to be proximal (109 proximal : 72 distal).

A tendency to sporulate became evident with the appearance of conjugant cells after incubation for $2 \mathrm{~d}$ at $30^{\circ} \mathrm{C}$ on YM solid medium. These were enlarged cells from which a long (up to 45 $\mu \mathrm{m})$ tube extended. The tube often became branched. Conjugant cells were more abundant toward the centre of a streak but seldom occurred with a frequency greater than about $0.3 \%$. Ascophores, with developing asci at their tips, began to appear after about $8 \mathrm{~d}$. Ascophores were very similar to conjugant cells in their general conformation but were easily distinguished from them when they reached maturity: the stalk or tube was wider and much sturdier, and the whole structure was more refractile. A small cell was usually attached to the basal cell, as already noted. Ascophores were infrequent in cultures of wild-type strains; the ratio of ascophores to conjugant cells seldom exceeded $1: 10$. The relationship between these two types of cells was not immediately apparent in such cultures but was clarified through the use of a mutant strain (see below).

Ascospores, when isolated and incubated on YEPD, germinated to produce lines that were apparently identical to the strain from which they were derived; they sporulated with the same low frequency. On the other hand, the rate of spore germination was very high, usually in excess of $95 \%$.

We found no evidence, whether from mixtures of the four strains or mixtures of genetically marked segregants, for the existence of stable mating types. Nor did we find any evidence that a stable diplophase is normal to the life-cycle of the species. We conclude, in agreement with Wickerham (1970), that the species is predominantly haploid and strongly homothallic, at least for the strains in this laboratory.

\section{Regeneration of conjugant cells and the production of homozygous diploids}

Despite the apparent absence of a diplophase in the normal life cycle, a simple method exists for producing diploid strains. This method was devised on the supposition that the diploid 


\section{Table 1. Location and frequency of occurrence of sites of mitotic activity in regenerating} conjugant cells taken from sporulating cultures of different ages

The sites of mitotic activity (budding) are abbreviated as follows: prox., proximal, in the base of the conjugant cell; cent., central, in the central region of the conjugant tube; dist., distal, in the tip of the conjugant tube.

\begin{tabular}{lccccccccc}
$\begin{array}{c}\text { Age of } \\
\text { sporulating } \\
\text { culture (d) }\end{array}$ & None & Prox. & Cent. & Dist. & \multicolumn{4}{c}{$\begin{array}{c}\text { Prox., Prox., Cent., } \\
\text { cent. }\end{array}$} \\
& 2 & 12 & 10 & 9 & 4 & 4 & 3 & 1 & 0 \\
$1-4$ & 7 & 10 & 14 & 21 & 0 & 3 & 2 & 0 & 1 \\
$5-8$ & 9 & 22 & 24 & 30 & 4 & 7 & 5 & 1 & 1
\end{tabular}

premeiotic nucleus might be prevented from entering meiosis by moving it from sporulation medium to a medium conducive to mitosis.

Using a micromanipulator, individual conjugant cells were isolated from $\mathrm{YM}$, transferred to sealed YEPD slabs, incubated at $30^{\circ} \mathrm{C}$, and inspected periodically under a microscope. Regeneration occurred afer a lag phase of several hours. At this time buds appeared at one or a few distinct sites on the conjugant cells. At most sites a bud was initiated about every $2 \mathrm{~h}$. In the majority of instances (84 out of 97) the regenerant cells, when picked and recultured, were typical of haploids in size, growth rate, and manner of sporulation. But 13 of the regenerating conjugant cells produced buds that were distinctly larger than normal, an indication of diploidy. In four instances this evidence was reinforced by the fact that the buds, when isolated, produced healthy cultures of large cells, which sporulated more abundantly than the parent strain and in a much shorter time ( $3 \mathrm{~d}$ as opposed to $8 \mathrm{~d}$ ). The other nine candidates for diploidy were less amenable to analysis; the large buds were either abortive or produced slow-growing nonsporulating cultures. Data relating to the regeneration of conjugant cells are presented in Table 1.

From the rate at which buds were initiated at specific sites (every $2 \mathrm{~h}$ ) it seems likely that a single functional nucleus is responsible for regeneration at any one site within the conjugant cell. Conjugant cells usually contain one functional nucleus, but sometimes they contain two or, more infrequently, three. These nuclei may be located in the basal cell (proximal), in the central region of the tube, or toward the tip of the tube (distal), but they tend to migrate toward the distal end of the tube. The diploidization process, by whatever mechanism it occurs, is not error-free since abortive cells and other genetic variants are produced in the process of regeneration. It now seems possible that these 'errors' occur in instances where regeneration is induced before the fusion process is completed.

\section{Vegetative growth and sporulation of diploids}

Although actively dividing diploid cells were larger than haploid cells, the two cell types were, in contrast to $S$. cerevisiae, identical in shape and in the randomized bipolar nature of cell division. For this reason it was not always easy to designate ploidy to a culture in the exponential growth phase by visual inspection. Differences were more obvious in sporulating cultures where, as mentioned previously, ascophores were produced more abundantly and more quickly by diploids than by haploids and the more fragile conjugant cells were absent. However, with the acquisition of mutant strains it has become evident that these differences also may, in some instances, be blurred. In this laboratory, the ploidy of a strain was most accurately determined from the morphology of ascophores; the majority of ascophores in haploid cultures had one or more cells attached to the basal cell, whereas those of diploid cultures were completely free of such attachments.

\section{Nuclear fusion in haploids}

Information about the mechanism by which diploidy is achieved in haploid cultures of $P$. tannophilus is of basic importance for genetic manipulation. It is thought that, in general, meiosis 
and ascus formation occur immediately after karyogamy and diploidization in budding homothallic yeasts that are stabilized in the haplophase (van der Walt, 1970). It now seems that diploidy in $P$. tannophilus is typically confined to such a transient state. No doubt there are exceptions in nature; an example is provided by NRRL Y2460 which, though haploid in our hands, was obviously diploid when first isolated. Furthermore, the conditions that were used in this study to induce diploidy must occasionally prevail in nature. Nevertheless, we have yet to obtain evidence that any haploid cultures contain sufficient diploid cells for them to be detected in the course of routine laboratory procedures.

Self diploidization could occur either by fusion of the immediate products of a mitosis or by fusion of two independent cells of a culture. The former process is considered to be the more primitive mode of diploidization (van der Walt, 1970). In devising genetic techniques for a homothallic organism, it is important to know which of these mechanisms is present. Certainly the fusion of independent cells would seem to provide a better opportunity for achieving interstrain crosses in the laboratory.

Previous publications do not clarify the behaviour of $P$. tannophilus in this regard; the fact that cells are often attached to the base of an ascophore could be a consequence of either some sort of bud-fusion event or fusion of a 'normal' cell to a conjugant cell. In the present study, the absence of any attachments to those regenerating conjugant cells that produced diploid clones suggested that nuclear fusion of the immediate products of a mitosis occurs within the conjugant cell, but did not exclude an alternative mechanism.

Positive evidence that the more primitive mechanism of nuclear fusion within a conjugant cell is, in fact, responsible for diploidy was obtained from a visual study of the progressive steps involved in the evolution of a vegetative cell to an ascophore. Wild-type haploids sporulate much too infrequently to provide good material for such a visual study of ascophore formation. However, the procedure is possible with some mutant strains. One such strain is the auxotrophic mutant, ade1-1. This mutant sporulates abundantly on a solid minimal medium. Cells were streaked thickly on a slab of this medium. The slab was sealed and, after incubation for $1 \mathrm{~d}$, individual cells were placed, with the aid of a micromanipulator, in close proximity to the mass of growing cells. These isolated cells were periodically examined with a microscope.

Conjugant cells began to appear on day 1 . These increased in number over a period of $3 \mathrm{~d}$. Ascophore formation commenced on day 4 with the appearance of a swelling either in the base of a conjugant cell or in the central region of a tube. This swelling, together with an adjacent region of the tube, became refractile. Within $7 \mathrm{~h}$ an outgrowth from the swelling had produced a complete ascophore. The less refractile remnants of the original conjugant cell eventually dropped away.

\section{Heterozygous diploids and tetrad analysis}

Although the life-cycle of $P$. tannophilus is, to all appearances, not conducive to the construction of heterozygous diploids, it is nevertheless possible to construct such diploids by a method that combines a procedure for selection of prototrophic cells with the procedure described previously for the production of diploids from regenerating conjugant cells.

Different stable auxotrophic mutants were mixed as a streak on YM plates and incubated at $30^{\circ} \mathrm{C}$. At daily intervals thereafter, samples were streaked on minimal agar plates. Prototrophic colonies first appeared on streaks prepared from $2 \mathrm{~d}$ old mixtures. Their frequency reached a maximum with $5 \mathrm{~d}$ old mixtures. The cultures derived from such colonies sporulated profusely at $3 \mathrm{~d}$. Heterozygosity was confirmed by tetrad analysis (Table 2.) Segregations were regular for each of four mutant loci, ade1-1, arg 1-1, lys1-1, and met1-1. Two of these loci, arg1-1 and $l y s 1-1$, were linked. The frequency of gene conversion was apparently normal.

The frequency of heterozygote formation, though entirely adequate for genetic purposes, was very low, not exceeding about one in $10^{6}$ cells. So far, we have been unable to detect the production of such diploids under any conditions other than those described above. Although the manner by which nuclear fusion of independent cells occurs is not clear, it is apparent that such fusion is correlated with the production of conjugant cells; the frequency of matings toward 
Table 2. Tetrad analysis in P. tannophilus

$\begin{array}{lccc}\text { Genes } & \begin{array}{c}\text { Parental } \\ \text { ditype }\end{array} & \begin{array}{c}\text { Non-parental } \\ \text { ditype }\end{array} & \text { Tetratype } \\ \text { ade1-1-arg1-1 } & 17 & 23 & 62 \\ \text { ade } 1-1-\text { lys } 1-1 & 21 & 21 & 74 \\ \text { arg1-1-lys1-1 } & 51 & 10 & 110 \\ \text { met1-1-lys } 1-1 & 10 & 8 & 51 \\ \text { ade1-1-met } 1-1 & 6 & 2 & 13 \\ \text { met1-1-arg1-1 } & 10 & 13 & 48\end{array}$

the centre of a mixed streak was about four times that at the edges. The growth of strains on YM prior to mixing did not, however, hasten the production of diploids.

Pachysolen tannophilus, though possessing a life cycle that is apparently unsuited to genetic studies, is, in fact, entirely amenable to genetic manipulation. This system is now available for an investigation of the phenomenon of pentose fermentation in yeast.

\section{REFERENCES}

Boidin, J. \& ADZET, J. (1957). Deux curieuses levuses isolées d'extraits tannants d'origine végétale: Pachysolen (nov. gen.) tannophilus nov. sp. et $P$. pelliculatus nov. sp. Bulletin de la Société Mycologique de France 73, 331-342.

SchneIdeR, H., WaNG, P. Y., Chan, Y. K. \& MALeszKa, R. (1981). Conversion of D-xylose into ethanol by the yeast Pachysolen tannophilus. Biotechnology Letters 3, 89-92.

Shirling, E. B. \& GotTlieb, P. (1966). Methods for characterization of Streptomyces species. International Journal of Systematic Bacteriology 16, 313-316.

VAN DER WALT, J. P. (1970). Criteria and methods used in classification. In The Yeasts, a Taxonomic Study, 2nd edn, pp. 34-111. Edited by J. Lodder. Amsterdam: North Holland Publishing Co.

Wickerham, L. J. (1970). Genus 14. Pachysolen. Boidin et Adzet. In The Yeasts, a Taxonomic Study, 2nd edn, pp. 448-454. Edited by J. Lodder. Amsterdam: North Holland Publishing Co. 